\title{
Dynamics Simulation of Stirling Engine for Solar Energy Based on the Time-Varying Support Stiffness
}

\author{
Junzhou Huo ${ }^{1}$, Hanyang $\mathrm{Wu}^{1}$ and Jing Chen ${ }^{*}, 2$ \\ ${ }^{1}$ School of Mechanical Engineering, Dalian University of Technology, Dalian 116024, China \\ ${ }^{2}$ School of Naval Architecture and Ocean Engineering, Dalian Ocean University, Dalian 116023, P.R. China
}

\begin{abstract}
In order to simulate the Stirling engine more easily, the stiffness and damping ratio of the crankshaft bearing are assumed to be steady-state in the research before, but this assumption is contrary to the real condition. Therefore, in this paper, a time-varying stiffness and damping ratio of the crankshaft bearing simulation method has been proposed. Compared with the simulation results of the crankshaft bearings with constant stiffness, the speed fluctuation coefficient of output shaft and crankshaft in time-varying stiffness model is increased by $10 \%, 24.6 \%$ and $13.7 \%$; the vibration displacement of the center mass of output shaft is decreased by $3.0 \%$; the average dynamic load on airframe is increased by $47.9 \%$. From the simulation results, it is found that the time-varying stiffness and damping ratio of the crankshaft bearing is significant to the characteristics of the Stirling engine dynamic response.
\end{abstract}

Keywords: Dynamics simulation, Stirling engine, time-varying stiffness.

\section{INTRODUCTION}

Stirling engine, also known as hot-air engine, is a closed cycle reciprocating power machine, which take gas as its working fluid. It can be used in many areas as clean and efficient power machine because it has so many features, such as broad fuel sources, high efficiency, less pollution, low noise, compact structure, easy maintenance and so on [1-4]. The crank and connecting rod mechanism is the first transmission mechanism for a Stirling engine. Crank linkage has a simple structure, and it can be flexible design according to the actual arrangement of the cylinders.

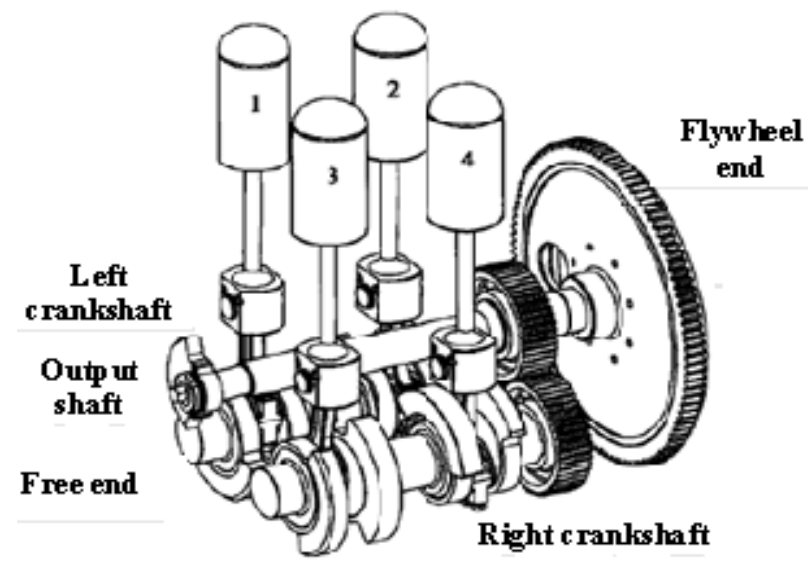

Fig. (1). Four-cylinder double-crank Stirling engine.

The schematic diagram of four-cylinder double-crank Stirling engine is shown in Fig. (1). Its connecting rod and crankshaft are connected by sliding bearing. Sliding bearing lubricants is very important to absorb shock, suppress instability and cool the bearing. The force and moment pass through the crankshaft bearings and the crankcase to supporting, which results in vibration of the Stirling engine $[5,6]$. Due to the complexity of its working mechanism, the oil film has a strong non-linearity [7]. However, most scholars ignore the time-varying stiffness of the sliding bearing, just do the dynamics simulation with a constant stiffness bearing, and the real work of Stirling engine cannot be reflected through this method. Thus, this paper studies the dynamic characteristics of Sliding bearing based on the timevarying stiffness and damping of the crankshaft bearings, and then we will make a comparison between the simulation results of constant stiffness and time-varying stiffness models.

\section{DYNAMICS SIMULATION MODEL ESTABLISHMENT}

\subsection{The Cyclic Loads of Cylinders}

Based on the theory of Schmidt cycle [8], the Stirling cycle of four-cylinder double-crank Stirling engine is analyzed. And then the pressure curves of hot chamber and cold chamber can be obtained, thus, we can acquire the pressure curve of piston rod easily. When the speed of the crankshaft is $1800 \mathrm{r} / \mathrm{min}$, we can get the pressure curve of piston rod while the cranks turn $1^{\circ}$ through the theoretical calculation, as shown in Fig. (2). Save the pressure values as txt formal and import it to ADAMS. The pressure curves of each cylinder, as the input load of dynamics model, are obtained by using spline functions AKISPL.

\subsection{Equivalent Model of Crankshafts}

Both of the crankshaft of Stirling engine has three sliding bearing as the support, and there are two inputs on each of 
them, so it is a over-constraint structure, which cannot be directly solved by ADAMS. Therefore, the crankshaft is split into three separate parts, and these parts are connected by the dummy through fixed hinge and universal hinge [9], as shown in Fig. (3). The fixed hinge limits all degrees of freedom; the universal hinge limits three translational degrees of freedom and the rotational degree of freedom about the $\mathrm{x}$ axis. So the statically indeterminate problem of the model has been solved.

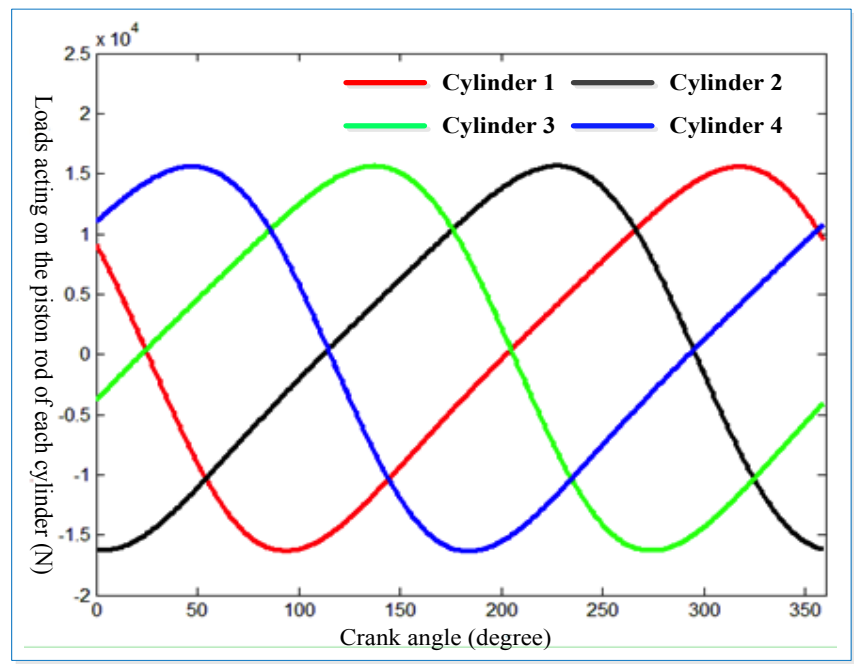

Fig. (2). Change curves of the pressure of the cylinders.


Fig. (3). The equivalent model of crankshaft.

\subsection{Equivalent Model of Sliding Bearings}

The stiffness and damping coefficients of each sliding bearing are caculated by [10] formula (1).

$k_{y y}=\frac{\overline{k_{y y}} W}{c}(N / m) \quad C_{y y}=\frac{\overline{C_{y y}} W}{c w}(N \cdot s / m)$

$k_{x x}=\frac{\overline{k_{x x}} W}{c}(N / m) \quad C_{x x}=\frac{\overline{C_{x x}} W}{c w}(N \cdot s / m)$

where $\mathrm{W}$ is the static load on the journal, $\mathrm{c}$ is the bearing radial clearance, $\omega$ is the angular velocity of the journal, and $\overline{k_{y y}}, \overline{k_{x x}}, \overline{C_{y y}}, \overline{C_{x x}}$ are the dimension stiffness and damping coefficients.

The stiffness and damping of the sliding bearing is timevarying according to the theoretical calculation method, because the pressure acting on the piston rod is time-varying. For example, the curves in Figs. $(\mathbf{4}, \mathbf{5})$ are the time-varying stiffness and damping of one of the main crankshaft bearing.
Generally, Bushing is used to simulate the support of sliding bearing. But, this method ignore the time-varying stiffness of bearing, and do the dynamics simulation with constant bearing stiffness and damping, which is very different from the actual situation. In ADAMS, dynamic equation of Bushing is defined as follows:

$$
\begin{gathered}
{\left[\begin{array}{l}
F_{x} \\
F_{y} \\
F_{z} \\
T_{x} \\
T_{y} \\
T_{z}
\end{array}\right]=-\left[\begin{array}{cccccc}
K_{11} & 0 & 0 & 0 & 0 & 0 \\
0 & K_{22} & 0 & 0 & 0 & 0 \\
0 & 0 & K_{33} & 0 & 0 & 0 \\
0 & 0 & 0 & K_{44} & 0 & 0 \\
0 & 0 & 0 & 0 & K_{55} & 0 \\
0 & 0 & 0 & 0 & 0 & K_{66}
\end{array}\right]\left[\begin{array}{l}
x \\
y \\
z \\
a \\
b \\
c
\end{array}\right]} \\
-\left[\begin{array}{ccccccc}
C_{11} & 0 & 0 & 0 & 0 & 0 \\
0 & C_{22} & 0 & 0 & 0 & 0 \\
0 & 0 & C_{33} & 0 & 0 & 0 \\
0 & 0 & 0 & C_{44} & 0 & 0 \\
0 & 0 & 0 & 0 & C_{55} & 0 \\
0 & 0 & 0 & 0 & 0 & C_{66}
\end{array}\right]\left[\begin{array}{l}
v_{x} \\
v_{y} \\
v_{z} \\
\omega_{x} \\
\omega_{y} \\
\omega_{z}
\end{array}\right]+\left[\begin{array}{l}
F_{1} \\
F_{2} \\
F_{3} \\
T_{1} \\
T_{2} \\
T_{3}
\end{array}\right]
\end{gathered}
$$

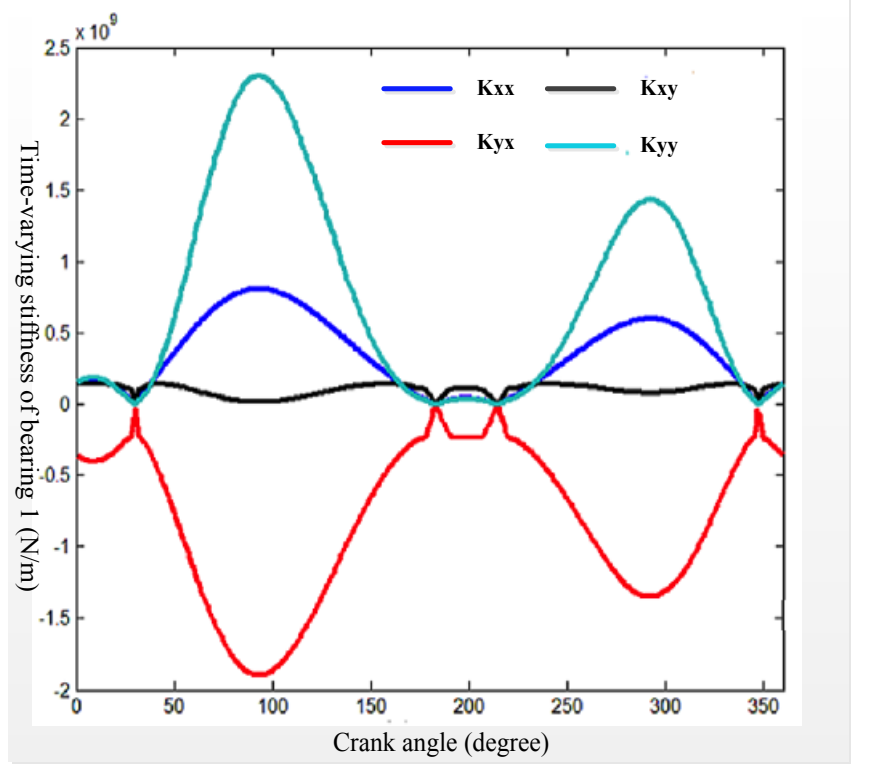

Fig. (4). Time-varying stiffness curve of main bearing 1 .

From the equation, we can find that the essence of Bushing is generalized force. The different between Bushing and generalized force is Bushing limits the radial angular displacement. Therefore, we use both generalized force and Bushing to simulate the time-varying stiffness of sliding bearing. The time-varying stiffness, as the coefficient of generalized force, are obtained by using spline functions AKISPL in ADAMS. The definition of a generalized force is defined as formula (3),

-AKISPL(TIME,0,SPLINE_1,0)*DX(M_235,M_236,M_236)

-AKISPL(TIME,0,SPLINE_2,0)*VX(M_235,M_236,M_236, (3) M_236) 


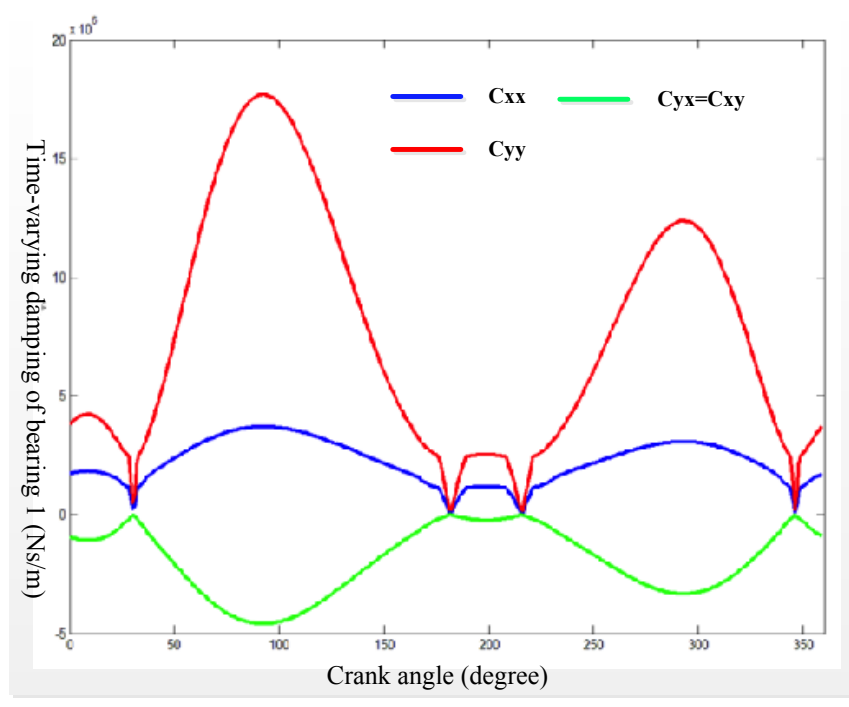

Fig. (5). Time-varying damping curve of main bearing 1 .

As shown in Fig. (6), the equivalent model of sliding bearings is obtained in ADAMS.

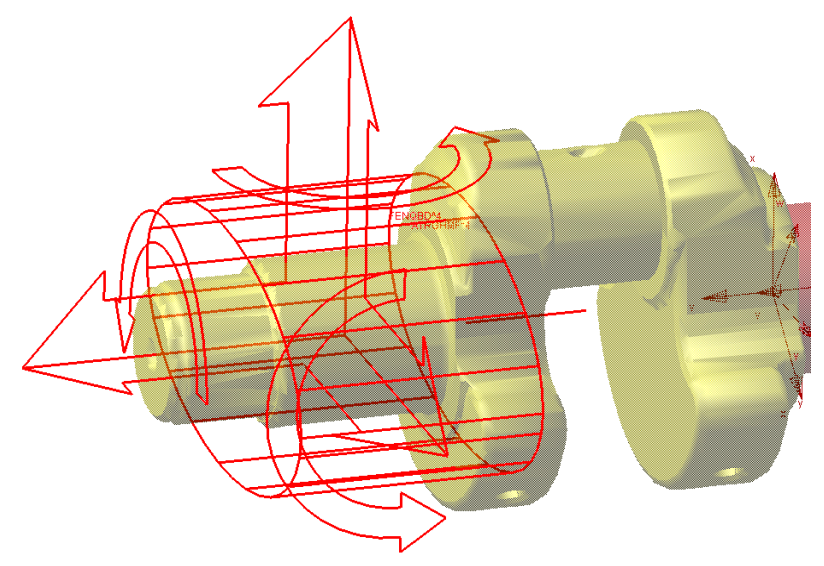

Fig. (6). The equivalent model of sliding bearing.



Fig. (7). The dynamic model of Stiring engine.

\subsection{The Dynamics Model in ADAMS}

In order to establish the dynamics model of the Stirling engine, it is necessary to simplify solid model reasonably. Entity the model created by UG into ADAMS, add the boundary and constraint to Stirling engine accoring to the real operating conditions. As shown in Fig. (7), the dynamics model of Stirling engine is established in ADAMS.

\section{THE SIMULATION RESULTS}

This paper studies the dynamic analysis of two Stirling engine equivalent model, one is based on constant stiffness and damping of sliding bearing, the other is time-varying.

Through the dynamics simulation, we have got some parameters which have influences on the Stirling engine such as the angular velocity fluctuations, centroid vibration of the crankshaft and output shaft, and the load on the body.

\subsection{Speed Fluctuations of Crankshafts and the Output Shaft}

Angular velocity curves of shafts under constant and time-varying stiffness bearing are shown in Figs. $(\mathbf{8}, \mathbf{9})$ respectively.

As the figure shown, it takes 4-5 s for Stirling engine to come to the steady state after started because of the inertia of the engine. When the Stirling engine works normally, the speed of crankshaft, output shaft will respectively stable at $1800 \mathrm{r} / \mathrm{min}, 1500 \mathrm{r} / \mathrm{min}$. And, we also can find that the trend of the two speed curves is the same. In order to study the different between the two simulation results, the speed fluctuation coefficient of each shaft during the last second are given in Table $\mathbf{1}$.

As the Table 1 shown, compared with the constant stiffness Stirling engine model, the speed fluctuation coefficient of left crankshaft, right crankshaft and output shaft of time-varying stiffness model has increased by $24.6 \%, 13.7 \%$ and $10 \%$.

\subsection{Centroid Vibrations of Crankshafts and the Output Shaft}

The centroid vibrations amplitudes of each shaft for the constant stiffness and time-varying stiffness Stirling engine model during the last secondare given in Table 2 .

As the Table 2 shown, compared with the simulation results of constant stiffness Stirling engine model, the centroid vibrations amplitudes of left crankshaft and right crankshaft has increased by $14.1 \%$ and $16.7 \%$, the centroid vibrations amplitudes of output shaft has reduced $3.0 \%$.

\subsection{Loads on the Engine Body}

The force curves on the engine body of the constant and time-varying stiffness bearing are shown respectively in Figs. (10, 11). In order to compare the load on the two Stirling engine, Table $\mathbf{3}$ gives the mean load on the body during the last second.

As Figs. (10, 11) and Table 3 shown, compared with the simulation results of constant stiffness Stirling engine model, the fluctuations of the force on engine body of the timevarying stiffness model has increased obviously, and the mean load on the engine body has increased by $47.9 \%$. Therefore, add the time-varying stiffness to the sliding bearing make a great influence on the engine body force. 


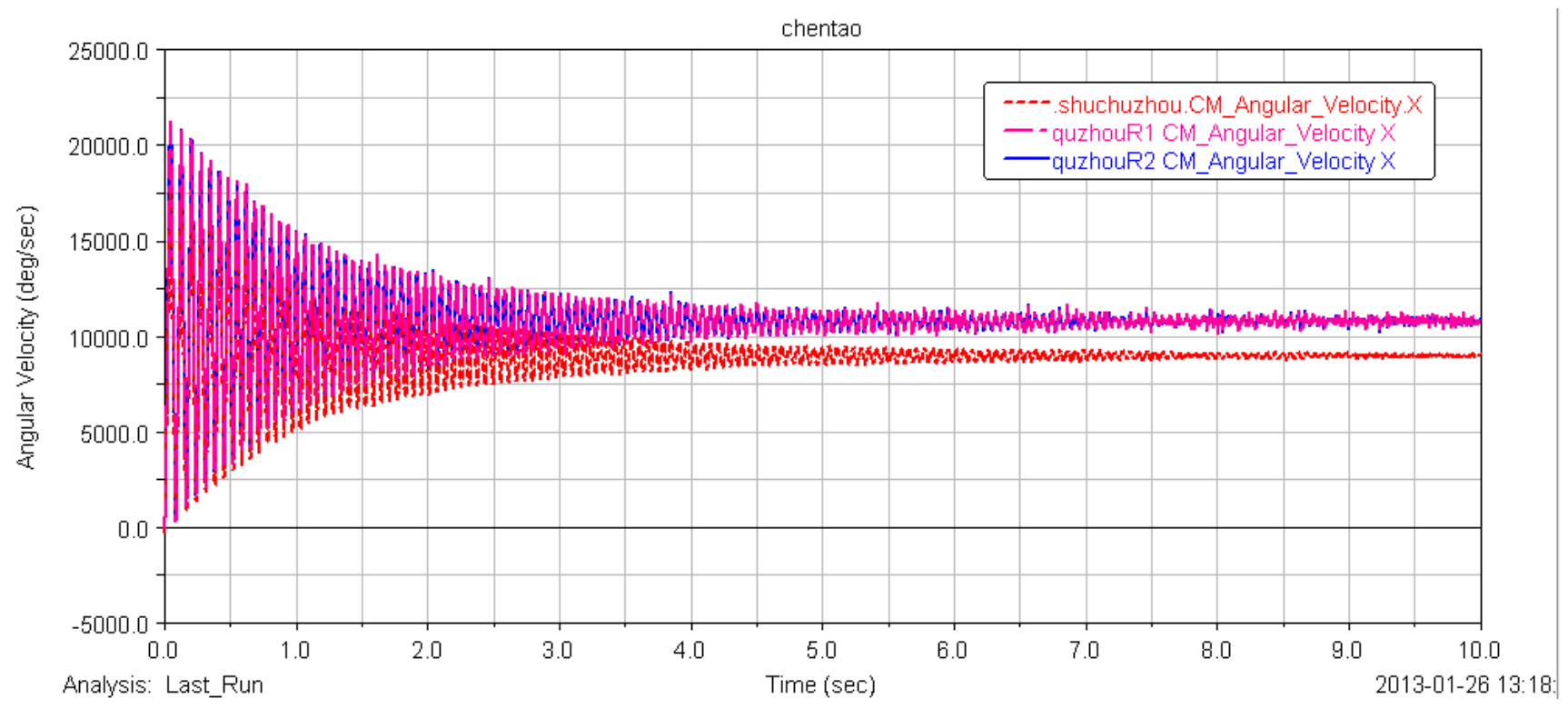

Fig. (8). Speed curves under constant stiffness.



Fig. (9). Speed curves under time-varying stiffness.

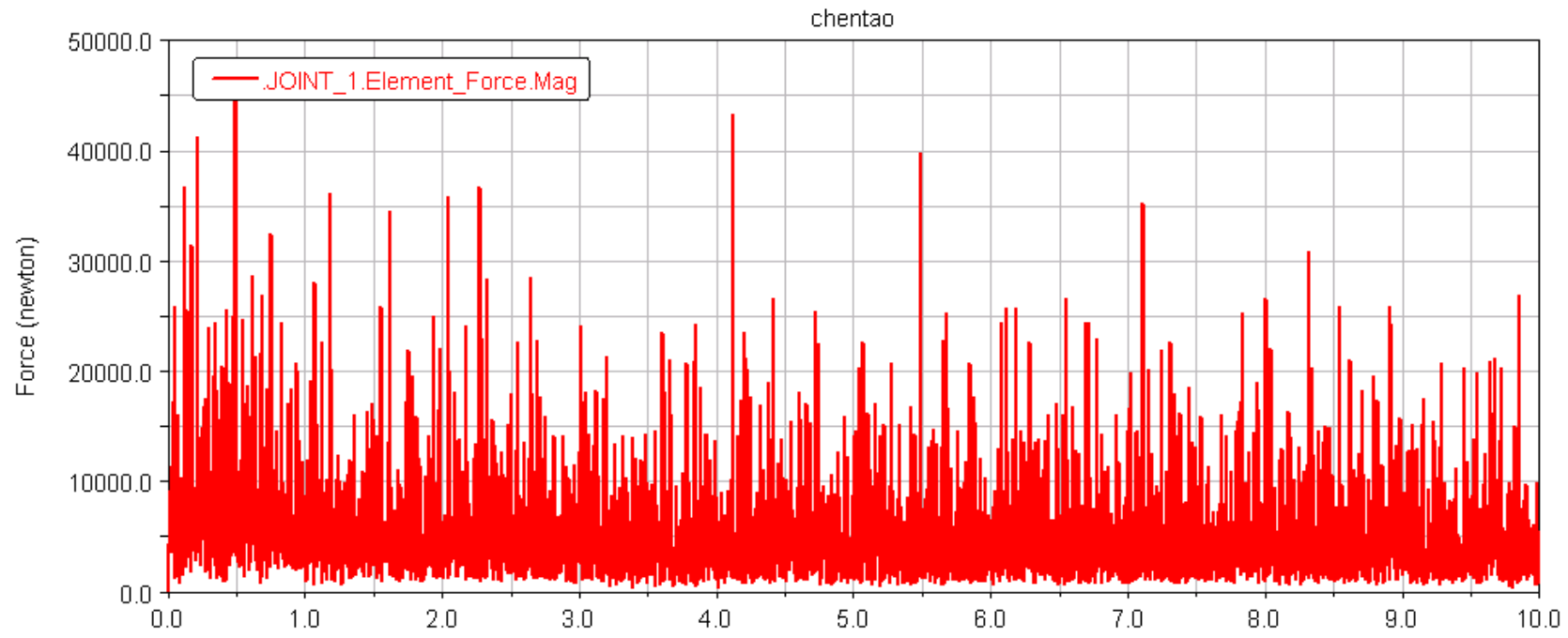

Fig. (10). Force on engine body under constant stiffness. 


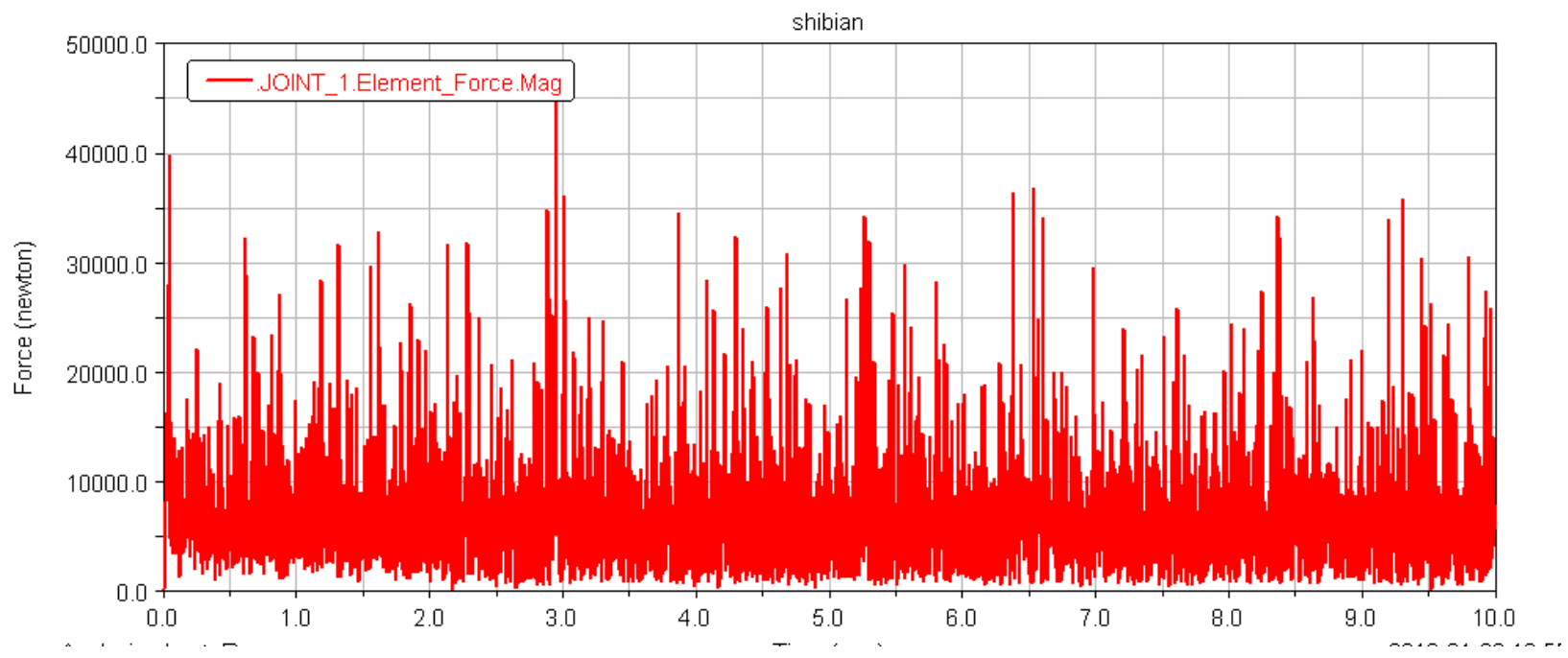

Fig. (11). Force on engine body under time-varying stiffness.

Table 1. Speed fluctuation coefficient of rotation shafts.

\begin{tabular}{|c|c|c|}
\hline $\begin{array}{c}\text { Speed Fluctuation } \\
\text { Coefficient }\end{array}$ & $\begin{array}{c}\text { Constant } \\
\text { Stiffness }\end{array}$ & $\begin{array}{c}\text { Time-Varying } \\
\text { Stiffness }\end{array}$ \\
\hline \hline Output shaft & $3.20 \%$ & $3.52 \%$ \\
\hline Left crankshaft & $8.32 \%$ & $10.37 \%$ \\
\hline Right crankshaft & $10.31 \%$ & $11.72 \%$ \\
\hline
\end{tabular}

Table 2. The vibration amplitude of rotation shaft centroid.

\begin{tabular}{|c|c|c|}
\hline $\begin{array}{c}\text { The Centroid Vibration } \\
\text { Amplitude (um) }\end{array}$ & $\begin{array}{c}\text { Constant } \\
\text { Stiffness }\end{array}$ & $\begin{array}{c}\text { Time-Varying } \\
\text { Stiffness }\end{array}$ \\
\hline \hline Output shaft & 6.7 & 6.5 \\
\hline Left crankshaft & 9.9 & 11.3 \\
\hline Right crankshaft & 9.6 & 11.2 \\
\hline
\end{tabular}

Table 3. The mean load on the engine body.

\begin{tabular}{|c|c|c|}
\hline & Constant Stiffness & Time-Varying Stiffness \\
\hline \hline Force $(\mathrm{N})$ & 4720 & 6983 \\
\hline
\end{tabular}

\section{CONCLUSION}

In this paper, we presented a equivalent model of a bushing force with a generalized force for the sliding bearings for their non-linearity of stiffness and damping ratio of the sliding bearings in work, so that we can have a more realistic simulation of the Stirling engine for its dynamic characteristics.

According to the simulations using the proposed timevarying stiffness and damping ratio model, we've found that time-varying stiffness and damping ratio on the Stirling engine have a certain impact on the speed fluctuation, vibration and load of crankshaft and output shaft. The speed fluctuation of left and right crankshaft and output-shaft has increased by $24.6 \%, 13.7 \%, 10 \%$; The centroid vibration amplitude of the output-shaft has reduced $3.0 \%$; The load to withstand has increased $47.9 \%$.

In this article, only the time-varying stiffness and damping ratio of the crankshaft bearing are considered, while the time-varying stiffness and damping ratio of the gear engagement are not included, and it should be developed in the following research.

\section{CONFLICT OF INTEREST}

The authors confirm that this article content has no conflict of interest.

\section{ACKNOWLEDGEMENTS}

This project is supported by National Natural Science Foundation of China (Grant No. 51375001, 51309045).

\section{REFERENCES}

[1] H. W. Li, L. S. Shi and Y. Q. Li, "The development and application of stirling engine", Energy Technol., vol. 31, pp. 228-231, 2010.

[2] G. Chen, "Stirling engine and its use prospects in China", Trans. Chin. Soc. Agric. Eng., vol. 9, pp. 126-129, 1993.

[3] D. H. Jin, "Green Power-Stirling Engine", World Science, Harbin Engineering University Press, China, 1997.

[4] W. T. Beale, J. G. Wood and B. F. Chagnot, "Stirling engine for developing countries," Am. Inst. Aeronaut. Astronaut., vol.12, pp. 1971-1975, 1980.

[5] G. Q. Ma, X. L. Bian, and Z. Y. Cao, "Study on the dynamics simulation of crank-connecting rod mechanism of engine", J. Hebei Univ. Technol. (Chinese), vol. 33, pp. 52-56, 2006.

[6] B. Li, C. L. Yang, and Y. Liu, "Analysis on characteristics of the movement and force of crank-connecting rod mechanism", Machinery (Chinese), vol. 33, pp. 10-12, 2006.

[7] G. J. Kostrzewsky and R. D. Flack, "Accuracy evaluation of experimentally derived dynamic coefficients of fluid film bearings", Tribol. Trans., vol. 33, pp. 105-114, 1990. 
[8] Z. Yang, "Simulation and optimum of the Stirling engine and the dish-Stirling solar power generation system", Ph.D. thesis, Beijing University of Technology, Beijing, 2008.

[9] A. Hu, "Dynamics simulation analysis of diesel engine crankshaft system based on ADAMS", Coal Mine Mach. (Chinese), vol. 31, pp. 62-65, 2010.
[10] A.A. Smaili and M.P. Khetawat, "Dynamic modeling of automotive engine crankshafts," Mech. Mach. Theory, vol. 29, pp. 995-1006, 1994.

(C) Huo et al.; Licensee Bentham Open.

This is an open access article licensed under the terms of the Creative Commons Attribution Non-Commercial License (http://creativecommons.org/licenses/by-nc/3.0/) which permits unrestricted, non-commercial use, distribution and reproduction in any medium, provided the work is properly cited. 